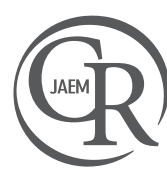

\section{A Case of a Serpentine-like Right Atrial Thrombus Causing Pulmonary Embolism}

\author{
Pulmoner Emboliye Neden Olan Yılanvari Sağ Atrial Trombüs Olgusu
}

Enbiya Aksakal1', Mücahit Emet², Hüsnü Değirmenci', Mustafa Uzkeser²

'Atatürk Üniversitesi Tıp Fakültesi, Kardiyoloji Anabilim Dalı, Erzurum, Türkiye

${ }^{2}$ Atatürk Üniversitesi Tıp Fakültesi, Acil Tıp Anabilim Dalı, Erzurum, Türkiye

\section{ABSTRACT}

Right atrial thrombi are rare but cause mortality in approximately $30-40 \%$ of cases. Echocardiography is important for determining the causes of the cardiac origin of pulmonary embolism, and, simultaneously, mobile thrombi can be rarely visualized in the right atrium and pulmonary artery. Thrombolytic therapy is a life-saving intervention in patients with a right atrial thrombus and massive pulmonary embolism. In this report, we present a case of a serpentine-like right atrial thrombus adhered to the interatrial septum, leading to pulmonary embolism. The interesting feature of this case is that mobile thrombi were simultaneously visualized in the right atrium and pulmonary artery by transthoracic echocardiography.

Keywords: Right atrial thrombus, pulmonary embolism, thrombolytic theraphy

Received: 02.04.2011 Accepted: 29.08.2011

\section{ÖZET}

Sağ atriyal trombüs nadirdir fakat yaklaşık \%30-40 ölüme neden olabilmektedir. Ekokardiyografi pulmoner embolinin kardiyak kökenli nedenlerinin belirlenmesinde önemlidir ve hareketli trombüs nadiren aynı anda sağ atriyum ve pulmoner arterde görüntülenebilir. Trombolitik tedavi sağ atriyal trombüs ve masif pulmoner emboli olan hastalarda hayat kurtarıcı girişimdir. Biz bu yazıda interatriyal septuma tutunan ve pulmoner emboliye yol açan yılanvari sağ atriyal trombüs olgusunu sunmayı amaçladık. Bu olgunun ilginç olan özelliği, hareketli trombüsler transtorasik ekokardiyografi ile sağ atriyum ve pulmoner arterde aynı anda görüntülenmiştir.

Anahtar Kelimeler: Sağ atriyal trombüs, pulmoner emboli, trombolitik tedavi

Geliş Tarihi: 02.04.2011 Kabul Tarihi: 29.08.2011

\section{Giriş}

Pulmoner emboli (PE) tanısı zor konan önemli bir morbidite ve mortalite nedenidir. Sağ atrial trombüslü olgularda PE insidansı \%97 iken mortalite \%44'ün üzerinde bildirilmiştir (1). PE'nin sık semptomlarından olan nefes darlığı, göğüs ağrısı, bayılma diğer klinik durumlarla karışmasına neden olmaktadır. Ekokardiyografi, PE tanı ve tedavisinde önemli bir yardımcıdır. Ekokardiyografi ile sağ kalp trombüsünün belirlenmesi PE tanısına önemli katkı sağlamaktadır. PE'de prognozu etkileyen en önemli faktör doğru ve hızlı olarak tanıya ulaşmaktır. Biz bu yazıda interatrial septuma tutunan ve PÉye neden olan yılanvari sağ atriyal trombüs olgusunu sunduk.

\section{Olgu Sunumu}

Uzun bir süredir romatoid artrit, kalça ve diz ekleminde artroz nedeni ile immobil olan 75 yaşında bayan hasta acil kliniğine şiddetli nefes darlığı, hırıltılı solunum, öksürük, sol yan ağrısı ve halsizlik şikayeti ile başvurdu. Tıbbi öyküsünde romatoid artrit ve immobilizasyon dışında özellik yoktu. Fizik muayenede, kalp sesleri ritmik ve taşikardikti. Mezokardiak odakta 3/6 sistolik üfürüm mevcuttu. Kan basıncı 80/50 mmHg, nabız 116 atım/dk ve solunum sayısı 28/dk idi. Solunum sesleri her iki akciğer bazalinde azalmıştı. Glaskow koma skalası 15 idi. Elektrokardiyografide sinüs ritmi ve $S_{1} Q_{3} T_{3}$ paterni mevcuttu. Akciğer PA grafide hafif kardiyomegali dışında patolojik görünüm yoktu. Alt extremite venöz Doppler ultrasonografide sol bacakta akut faz derin venöz tromboz tespit edildi. Kan tetkiklerinde D-dimer 6402 ng/mL, troponin I 1.4 Mg/L bulundu. Arteryel kan gazı incelemesinde oksijen

Bu olgunun özeti 24-27 Mart 2011 tarihinde Antalya'da yapılan 7. Kardiyoloji ve Kardiyovasküler Cerrahide Yenilikler Kongresi'nde sunulmuştur. 
saturasyonu \%89, parsiyel oksijen basınc 51 mmHg, parsiyel $\mathrm{CO}_{2}$ basıncı 24 mmHg olarak bulundu. Transtorasik ekokardiyografide (TTE) oldukça hareketli, bir ucu sağ atriyumda interatriyal septuma tutunan ve serbest ucu triküspit kapaktan sağ ventrikül apeksine doğru uzanım gösteren $1 \times 7 \mathrm{~cm}$ ebatlarında yılanvari trombüs izlendi (Resim 1a). Ayrıca parasternal aks görüntüde pulmoner arterde $0.5 \times 0.5$ cm ebatlı hareketli trombüs izlendi (Resim 1b). TTE'de sol ventrikül fonksiyonları normal, interventriküler septum paradoks hareketli, sağ kalp dilate, orta dereceli triküspid yetersizliği, pulmoner hipertansiyon (60 mmHg) tespit edidli. PE şüphesi olan hasta Wicki ve Wells skorlamasına göre orta riskli grup olarak değerlendirildi. Bilgisayarlı tomografi-pulmoner anjiyografi çekildi, ana pulmoner arterde lümende orta-ileri darlığa yol açan $0.8 \times 0.8 \mathrm{~cm}$ ebatında trombüs tepit edildi. Hasta kardiyoloji yoğun bakım kliniğine yatırıldı, kan basıncında ilerleyici düşme, taşikardi, solunum sıkıntısında artma ve taşipne nedeni ile dobutamin infüzyonu (10 mikrogram/kilogram/dakika) ve $\% 0.9 \mathrm{NaCl}$ infüzyonu (100 cc/saat) başlandı ve dozları giderek arttırıldı. Hemodinamik bozukluk nedeni ile trombolitik tedavi endikasyonu olan hastaya doku plazminojen aktivatörü (t-PA) 10 mg bolusu takiben 90 mg intravenöz infüzyon şeklinde iki saatte uygulandı. Takibinde hemodinamik düzelme ile birlikte ekokardiyografide sağ atriyal trombüsün küçüldüğü ve pulmoner arterdeki trombüsün ise tamamen kaybolduğu görüldü. İkinci gün yapılan kontrol TTE'de sağ atriyum yerleşimli yılanvari trombüsün küçüldüğü, interatrial septumun intakt olduğu ve pulmoner arterde trombüs olmadığı tespit edildi ve bu durum transözafajiyal ekokardiyografi (TEE) ile doğrulandı. Sağ atriyum trombüsünün küçüldüğü görülünce unfraksiyone heparin infüzyonuna (5000 ünite bolus ve 1000 ünite/saat) başlandı. Kırksekiz saat sonra yapılan TTE'de sağ atriyal trombüsün tamamen eridiği görüldü (Resim 2). Hasta klinik iyileşmeden sonra oral antikoagülan (Warfarin $5 \mathrm{mg}$ ) tedavi ile taburcu edildi. Hastanın altı aylık takibinde herhangi bir olumsuz olay gözlenmedi.

\section{Tartışma}

Sağ atriyum trombüsleri, sağ atriyumda lokal olarak gelişebilecekleri gibi ven yatağının başka bölgelerinden buraya ilerleyebilirler. Çok tipik olarak sağ kalp trombüsleri dar, uzun, çok hareketli, yılanvari (serpenjinöz) ve filiform yapıda izlenmekte olup daha çok alt extremite venlerinden ve nadiren lokal yerleşimli olarak ortaya çıkmaktadırlar (2). Sağ atriyum içerisinde bazı bölgeler pıhtının tutunması için zemin oluşturmaktadır. Triküspid kapak, östakiyan kapakçık, patent foramen ovale ve interatriyal septum bu yapıların başında gelmektedir (3). Sağ atriyal hareketli trombüsler erken müdahale edilmediği takdirde ciddi sonuçları olan ve ölüme yol açan bir durumdur. Sağ kalp kökenli trombüsler PE'ye neden olduklarından kötü prognozludurlar (4). Ancak pulmoner tromboembolinin esas kayanağı alt ekstremiteler olup sağ kalp trombüslerine bağlı PE nadirdir (5).

Pulmoner emboli tanısında konvansiyonel pulmoner anjiyografi, bilgisayarlı-pulmoner anjiyografi ve sintigrafi kullanılmaktadır. Ekokardiyografi PE'li hastaların \%4-20'sinde sağ kalp trombüslerinin tespit edilmesini sağlar (6). Ekokardiyografi, PE'nin kardiyak nedeninin saptanmasında ve eş zamanlı görülen pulmoner arter ve sağ atriyum mobil trombüsünün belirlenmesinde son derece önemlidir. Sağ atriyal trombüs mevcudiyetinde patent formane ovaleye tutunan ve sol atriyumda da devamlıı̆̆ı olan trombüsler olabilmektedir. Bu du-
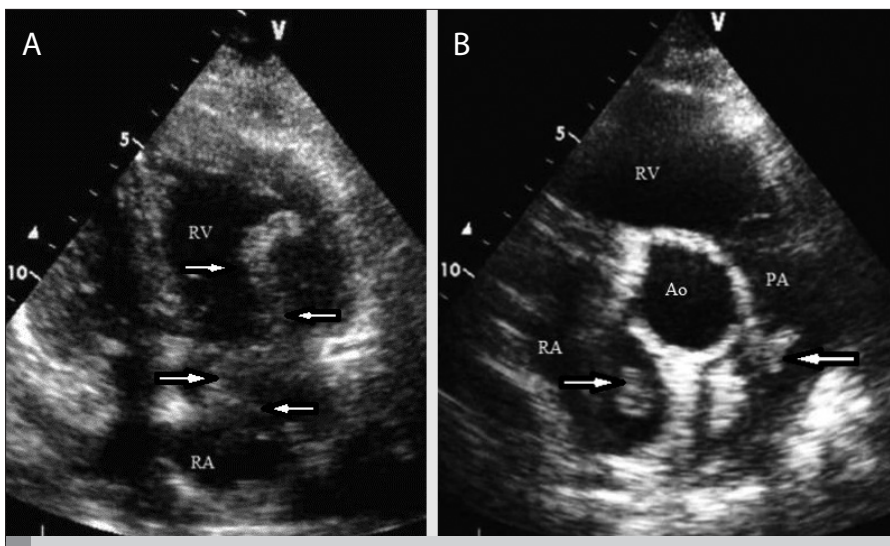

Resim 1. A) Transtorasik ekokardiyografide apikal dört boşluk görüntülemede trombüs sağ atriyumdan sağ ventrikül apeks'e uzanım göstermektedir, B) Transtorasik ekokardiyografide parasternal kısa aks görüntülemede sağ atriyum ve pulmoner arterde trombüsler eşzamanlı görünmektedir

Ao: Aorta, PA: Pulmoner arter RA: Sağ atriyum, RV: Sağ ventrikül, oklar; trombüs

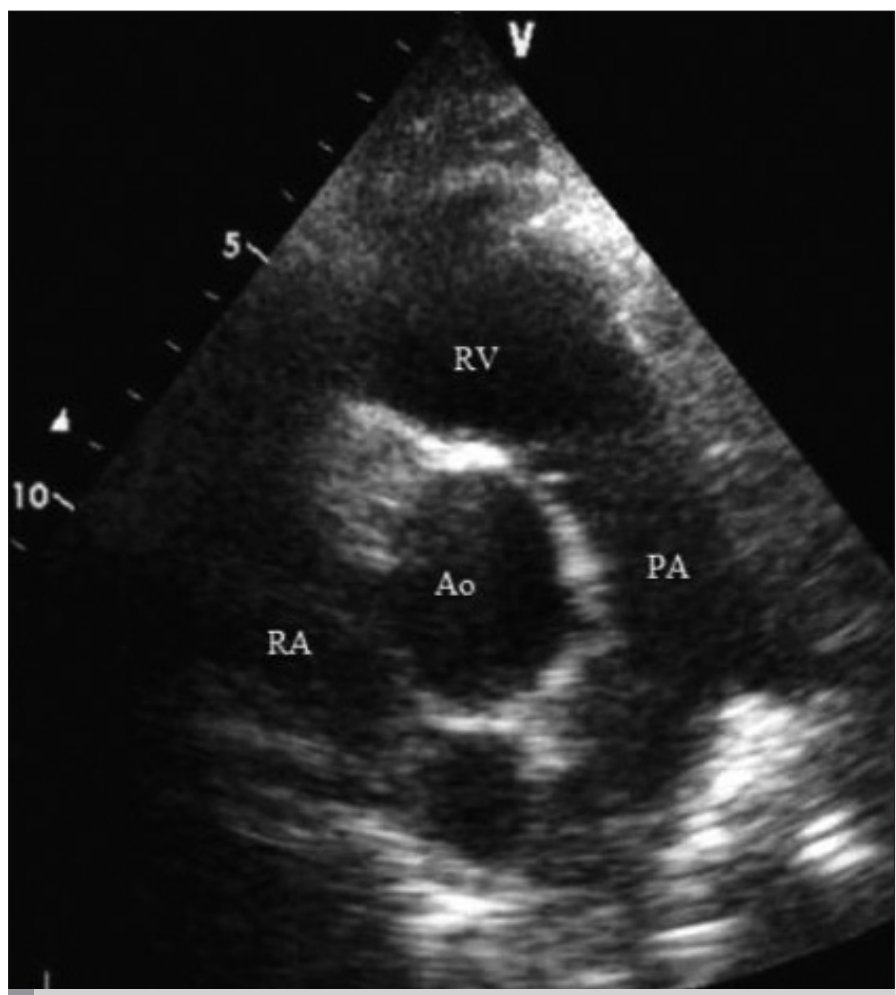

Resim 2. Transtorasik ekokardiyografide parasternal kısa aks görüntülemede tedavi sonrası trombüslerin kaybolduğu görülmektedir

Ao: Aorta, PA: Pulmoner arter, RA: Sağ atriyum, RV: Sağ ventrikül

rumlarda sağ atriyal trombüslerin lokalizasyonu ve patent foramen ovale ile ilişkisi TEE veya kardiyak manyetik rezonans görüntüleme ile doğrulanmalıdır (7)

Fabijanic ve ark. (8) sağ atriyal trombüs ve PE olan hastada trombüsün yapısı ve lokalizasyonun belirlenmesi için TTE'ye ek olarak TEE kullanmışlardır. Hohn ve ark. (9) spinal cerrahi sonrası PE'den şüphe- 
lenilen hastada hızı tanı için TEE'yi kullanmışlardır, TEE ile sağ atriyal trombüs ve PE saptanan hasta 100 mg t-PA ile tedavi edilmiştir. Soydinç ve ark. (10) 65 yaşındaki hastada sağ kalp trombüsü ve PE tanısını yalnızca klinik ve ekokardiyografik olarak koymuş ve başarılı trombolitik tedavi uygulamışlardır. Yılmaz ve ark. (11) hazırlayıcı faktörleri bulunan, klinik olarak PE için yüksek riskli ve genel durumu akciğer sintigrafisi ve/veya pulmoner anjiyografi için uygun olmayan olgularda PE tanısında ekokardiyografinin kullanılabileceğini bildirmişlerdir. Biz de sunduğumuz olguda TTE'de görülen sağ atriyal trombüsün tedavi sonrası lokalizasyonu, büyüklüğü, interatriyal septum ve patent foramen ovale ile ilişkisinin tespiti için TEE'yi kullandık.

Sağ kalp trombüsü ile birlikte olan PE'lerde optimal tedavi tartışmaııdır. Avrupa Kardiyoloji Derneği (ESC) ve Amerikan Göğüs Hekimleri Birliği (ACCP) kılavuzlarında akut PE ile birlikte sağ kalp trombüsü buIunan olgular hemodinamik instabiliteden bağımsız olarak yüksek riskli grup olarak belirlenmiş ve bu grupta acil tedavi önerilmiştir $(12,13)$. PE'de tedavi seçenekleri cerrahi tedavi, trombolitik tedavi, tek başına heparin tedavisi veya bunların kombinasyonları şeklindedir. Tedavi seçeneği hakkında kanıta dayalı tavsiye bulunmamakla birlikte mortalite oranın daha az olması nedeni ile birçok çalışma ve olguda trombolitik tedavinin daha avantajlı olduğu bildirilmiştir (7). Cerrahi tedavi yapılan hastalarda mortalite oranı trombolitik tedavi verilenlere göre iki kat daha yüksek bulunmuştur (6). Yüksek riskli, hemodinamik bozukluğu olan, hipotansiyon ve şok bulguları olan, genel durumu PE nedeni ile giderek bozulan olgularda trombolitik tedavi endikasyonu vardır $(12,13)$. Trombolitik tedavi sonrası trombüsün fragmanlara ayrılması ile embolizasyona yol açabileceği ancak bu durumun hemodinamik açıdan ciddi sonuçlara yol açmadığı da belirtilmektedir (14). Chartier ve ark. (15) mortalite oranlarını cerrahi tedavi için \%47.1, trombolitik tedavi için \%22.2 ve tek başına heparin için \%62.5 olarak bildirmişlerdir. Huang ve ark. (7) solucan benzeri'sağ kalp trombüsü olan hastada trombolitik tedaviyi reddetmesi nedeni ile tek başına heparin tedavisi uygulamış ancak olgu on iki saat içinde ölümle sonlanmıştır. Saura ve ark. (16) patent foramen ovaleye tutunan sağ ve sol atriyal kısımları olan 'silindirik' sağ kalp trombüsü olan olguda başarılı cerrahi tedavi uygulamışlardır. Tsarouhas ve ark. (17) sağ atriyal trombüs ve PE olan olguda tanıyı transözafajiyal ekokardiyografi ile doğrulayıp, başarılı trombolitik tedavi uygulamışlardır.

Biz bu yazıda tıbbi literatürdeki diğer olgulardan farklı olarak TTE ile eş zamanlı olarak pulmoner arter ve sağ atriyal trombüs tespit ettiğimiz olguyu sunduk. Tanıda TTE, TEE ve bilgisayarlı tomografipulmoner anjiyografi'yi kullandığımız olguda trombolitik tedavi ile sağ atriyal trombüs ve pulmoner emboli başarılı olarak tedavi edildi.

\section{Sonuç}

Sağ atriyal trombüsler nadir görülmekle birlikte sıklıkla pulmoner emboliye neden olmaktadır. Mortalitesi yüksek olan bu olguların tanısında ekokardiyografi önemli bir araçtır ve trombolitik tedavi hayat kurtarıcı bir seçenektir.

\section{Çıkar çatışması}

Yazarlar herhani bir çıkar çatışması bildirmemişlerdir.

\section{Kaynaklar}

1. Torbiki A, Galie N, Covezzoli A, Rossi E, Goldhaber S. Right heart thrombi in pulmonary embolism: results from the International Cooperative Pulmonary Embolism Registry. J Am Coll Cardiol 2003; 41: 2245-51.

2. Chartier L, Béra J, Delomez M, Asseman P, Beregi JP, Bouchart JJ, et al. Freefloating thrombi in the right heart: diagnosis, management, and prognostic indexes in 38 consecutive patients. Circulation 1999; 99: 2779-83. [CrossRef]

3. Covarrabias EA, Shekh MU, Fox LM. Echocardiography and pulmonary embolism. Ann Intern Med 1977; 87: 720-1.

4. Kinney EL, Wright RJ. Efficacy of treatment of patients with echocardiographically detected right-sided heart thrombi: a meta-analysis. Am Heart J 1989; 118: 569-73. [CrossRef]

5. Moser KM. Pulmonary thromboembolism, in Harison's Principles Of Internal Medicine, 12 th edition. Wilson JD, Braunwald E, Isselbacher KJ, Petersdorf RG, Martin JB, Fauci AS, Root RK, New York, McGraw- Hill 1991, pp 1090-6.

6. Erkut B, Koçak H, Becit B, Şenocak H. Massive pulmonary embolism complicated by a patent foramen ovale with stradding thrombus: report of case. Surgery Today 2006; 36: 528-33. [CrossRef]

7. Huang SL, Chien CH, Chang YC. A floating thrombus of the right ventricle in severe massive pulmonary embolism. Am J Emerg Med 2008; 26: 1071. e1-2.

8. Fabijanić D, Rudež I, Radić M, Unić D, Barić D, Kardum D. Pulmonary embolism due to the right atrial thrombus mimicking atrial myxoma. Chin Med J 2010; 123: 2483-5.

9. Hohn A, Trojan S, Poels M, Sakka SG, Wappler F. Fulminant pulmonary artery embolism in the early postoperative phase. Use of transesophageal echocardiography in acute diagnostics. Anaesthesist 2010; 59: 812-7. [CrossRef]

10. Soydinç S, Davutoğlu V, Yıldııım C, Ünay N, Küçükdurmaz Z. Ekokardiyografiyle saptanan mobil sağ ventrikül trombüsü ve trombolitik ajanla başarilı tedavi edilen masif pulmoner emboli olgusu. Turk J Emerg Med 2004; 4: 78-80.

11. Yilmaz M, Beyan E, Uçar O, Koşan B, Arduç A, Abayli E. A case of acute pulmonary thromboembolism with a mobile thrombus in right ventricle detected with echocardiography. Anadolu Kardiyol Derg 2008; 8: E34.

12. Kearon C, Kahn SR, Agnelli G, Goldhaber S, Raskob GE, Comerota AJ, et al Antithrombotic therapy for venous thromboembolic disease: American College of Chest Physicians Evidence-Based Clinical Practice Guidelines (8th edn). Chest 2008; 133: 454S-545S.

13. Torbicki A, Perrier A, Konstantinides S, Agnelli G, Galiè N, Pruszczyk P, et al. Guidelines on the diagnosis and management of acute pulmonary embolism: the Task Force for the Diagnosis and Management of Acute Pulmonary Embolism of the European Society of Cardiology (ESC). Eur Heart J 2008; 29: 2276-315. [CrossRef]

14. Cracowski JL, Tremel F, Baguet JP, Mallion JM. Thrombolysis of mobile right atrial thrombi following severe pulmonary embolism. Clin Cardiol 1999; 22: 151-4. [CrossRef]

15. Chartier L, Béra J, Delomez M, Asseman P, Beregi JP, Bauchart JJ, et al Free-floating thrombi in the right heart: diagnosis, management, and prognostic indexes in 38 consecutive patients. Circulation 1999; 99: 2779-83. [CrossRef]

16. Saura D, García-Puente J, Oliva MJ, Cerdán MC, Gutiérrez F, de la Morena $\mathrm{G}$, et al. Treatment of right heart thromboemboli: the need of a randomized multicentre trial. Int J Cardiol 2009; 134: 419-20. [CrossRef]

17. Tsarouhas K, Kafantaris I, Antonakopoulos A, Limberopoulos G, Kouzanidis I, Vavetsi $S$, et al. Free floating thrombus in the right atrium causing massive pulmonary embolism. Int J Cardiol 2010; 138: e21-3. [CrossRef] 